\title{
Weight related health status of patients treated by dietitians in primary care practice: first results of a cohort study
}

\author{
Elisabeth Govers ${ }^{1,3^{*}}$, Jacob C Seidell ${ }^{1}$, Marjolein Visser ${ }^{1,2}$ and Ingeborg A Brouwer ${ }^{1}$
}

\begin{abstract}
Background: Overweight and obesity are common in the Netherlands: in $200651 \%$ of adult men and $42 \%$ of adult women were overweight; $10 \%$ of men and $12 \%$ of women were obese. Patients with overweight or obesity in the Netherlands are often referred to dietitians in primary care for weight loss treatment. We followed a prospective observational cohort to study the effectiveness of this treatment and present the baseline results in this article.

Methods: We invited dietitians throughout the country, who completed at baseline a questionnaire for each patient including weight, stature, waist circumference, age, gender, morbidities, medication, education level, ethnicity, referral, treatment expectations, history of previous weight loss attempts, and exercise.

Results: At baseline data from 1546 patients were obtained from 158 dietitians working in 26 practices. The majority (73\%) of patients were obese (BMl $\left.\geq 30 \mathrm{~kg} / \mathrm{m}^{2}\right)$; and $10 \%$ had a BMl of $40 \mathrm{~kg} / \mathrm{m}^{2}$ or more. The majority of patients (94\%) had a high to extremely high weight related health risk (WRHR): (BMI $25-30 \mathrm{~kg} / \mathrm{m}^{2}$ with comorbidities, or BMl $30-35 \mathrm{~kg} / \mathrm{m}^{2}$ without comorbidities, up to BMI $\geq 35$ with comorbidities and BMI $\geq 40$ with or without comorbidities). More than half (57\%) had comorbidities and a long history of weight loss attempts. An extremely high WRHR was seen in $24.5 \%$ of the sample. Patients with very high to extremely high WRHR often had type 2 diabetes mellitus; hypertension; dyslipidaemia; osteo arthritis; and sleep apnoea. Patients of middle and old age had a higher risk for very high and extremely high WRHR. Those with other comorbidities and those who asked for referral themselves had a lower risk.
\end{abstract}

Conclusion: The study was effective in recruiting dietitians to participate. The sample is representative for dietitians working in primary care. The majority of patients (94\%) had a high to extremely high weight related health risk (WRHR).

Keywords: Dietitian, Weight related health risk level, Patient characteristics, Obesity, Primary care

\section{Background}

In the Netherlands the prevalence of overweight and obesity has risen to $47.2 \%$ overweight and $11.8 \%$ obese citizens in 2011, in the population from age 15 and up [1]. These figures are based on self-reported weights and therefore likely to be underestimated as both men and women have been shown to under estimate their weight by $26 \%$ and $30 \%$ [2]. Patients with overweight and

\footnotetext{
* Correspondence: egovers@amstelring.nl

1 Department of Health Sciences and the EMGO Institute for Health and Care Research, Faculty of Earth and Life Sciences, VU University Amsterdam, De Boelelaan 1085, 1081 HV Amsterdam, The Netherlands

${ }^{3}$ Amstelring Foundation for Primary Care, Amstelveen, The Netherlands

Full list of author information is available at the end of the article
}

obesity - with and without comorbidities - are often referred to dietitians in primary care or visit the dietitian on their own initiative $[3,4]$. Dietitians work in primary care practices at the same location as the general physician, or have their own practice place close to the local health facilities. They may work solitarily or be part of a larger organisation that supplies services to a number of practices. They are paid by the health insurance of their patients for a limited number of hours (minimum three, maximum six hours), dependent on the patients' personal insurance policy. 
A recent economic report showed the benefits of treatment by dietitians of patients with multiple weight related chronic conditions in the Netherlands [5]. Several studies have been published in the US and the United Kingdom showing effects of weight loss treatment by dietitians [6-11]. To get an insight in dietary treatment of these patients we designed a prospective observational cohort study in which we included a large number of patients from more than twenty practices of dietitians in primary care across the country. For the complete study we phrased the research question as: "What are the determinants of weight loss and what are the success rates in patients treated by dietitians in primary care?" In this article we describe the characteristics of the population.

\section{Methods}

We designed the study as a prospective observational cohort study in which we followed patients who are treated in dietary practices for weight loss and weight maintenance for two years. We developed questionnaires, based on a survey in 2005, in which methods of weight management of 36 practices of dietitians in primary health care were evaluated, and which were representative for methods commonly used by dietitians. The intervention period ran up to one year; after one year a combination of intervention and weight maintenance took place and the second year long-term was weight maintenance only.

\section{Recruitment of dietitians}

We approached the 36 practices again and asked dietitians to participate in the current study. As a result 140 dietitians from 20 practices responded positively. Furthermore we added a letter to the Journal of the Dutch Association of Dietitians (2000 copies; 90\% of registered dietitians have a subscription to this journal) to invite dietitians in primary health care to volunteer for this study. As a result 50 dietitians from another 12 practices responded positively. Dietitians from six practices decided not to participate because of time constraints. In total 190 dietitians from 26 dietetic practices responded positively. One of the authors (EG) went to each practice to explain the purpose of the study and to train the dietitians on how to collect the data in a standardized way. In addition, the Dutch guideline on obesity treatment was carefully explained.

Eight dietitians coordinated the study in their team without treating patients themselves. Finally, of the initial

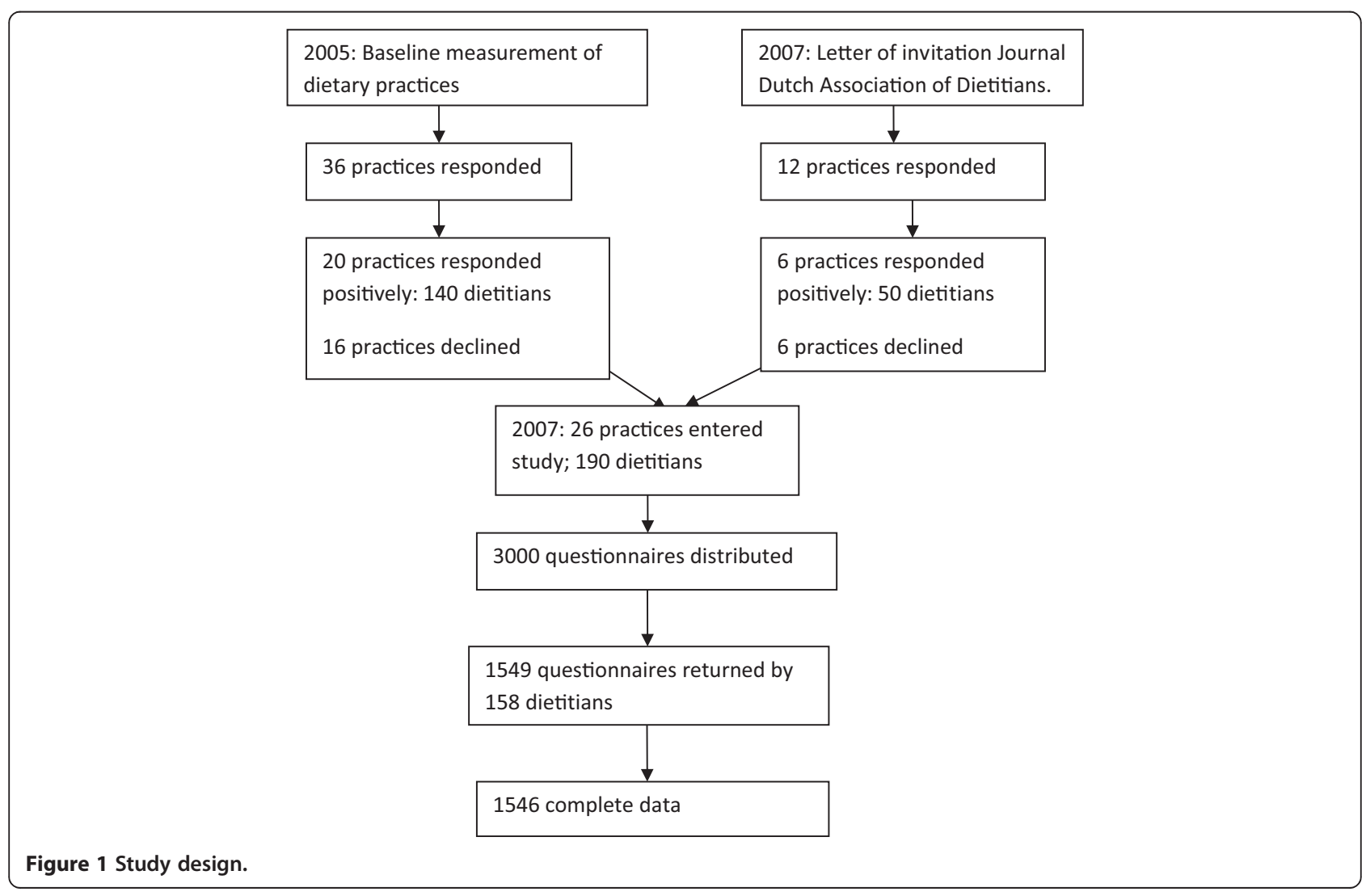


190, 156 dietitians from 26 practices recruited patients in the study; 26 dietitians decided not to participate in the study (Figure 1) for the following reasons: a too high work load, pregnancy, or seeing too few patients because of management tasks. In 21 of the practices a team of dietitians was involved; five practices consisted of only one dietitian.

\section{Recruitment of patients}

The period of recruitment was from March through July 2007. The dietitians themselves recruited new patients with and without comorbidities who visited on their own initiative or were referred to their practice for weight loss treatment. No specific instructions were provided on how to recruit these patients, other than the

Table 1 Baseline characteristics of the adult study sample

\begin{tabular}{|c|c|c|c|c|}
\hline & Total sample (\%) & Male (\%) & Female (\%) & $\begin{array}{l}\text { Chi square test } \\
P \text { value }\end{array}$ \\
\hline $\mathrm{N}$ & 1546 & 464 & 1082 & \\
\hline Age year; mean \pm SD & $49 \pm 14.7$ & $52 \pm 13.7$ & $48 \pm 15.0$ & \\
\hline 19-44 (young) & $402(26.0)$ & $82(17.6)$ & $320(29.5)$ & $<0.001$ \\
\hline 44-64 (middle aged) & 749 (48.4) & $234(50.5)$ & $515(47.6)$ & \\
\hline$\geq 65$ (old) & 395 (25.6) & $148(31.9)$ & $247(22.9)$ & \\
\hline $\mathrm{BMI} \mathrm{kg} / \mathrm{m}^{2} ;$ mean $\pm \mathrm{SD}$ & $33.5 \pm 5.4$ & $33.5 \pm 5.0$ & $33.5 \pm 5.5$ & \\
\hline$<25$ & $21(1.8)$ & $7(1.5)$ & $14(1.1)$ & 0.52 \\
\hline $25-29.9$ & $386(24.9)$ & $106(23.0)$ & $280(26.0)$ & \\
\hline $30-34.9$ & $616(39.8)$ & $199(43.0)$ & $417(38.7)$ & \\
\hline $35-39.9$ & $360(23.3)$ & $106(23.0)$ & $254(23.7)$ & \\
\hline$\geq 40$ & $157(10.2)$ & $44(9.5)$ & $113(10.5)$ & \\
\hline Weight - kg; mean \pm SD & $97.8 \pm 18.5$ & $\begin{array}{l}108.6 \pm \\
18.3\end{array}$ & $93.1 \pm 16.5$ & \\
\hline Waist - cm; mean \pm SD & $109 \pm 13.9$ & $\begin{array}{l}116 \pm \\
12.6\end{array}$ & $106 \pm 13.5$ & \\
\hline \multicolumn{5}{|l|}{ Waist } \\
\hline Small $^{1}$ & $20(1.4)$ & $9(2.0)$ & $11(1.1)$ & 0.26 \\
\hline Medium $^{2}$ & $78(5.3)$ & $27(6.0)$ & $51(5.0)$ & \\
\hline $\operatorname{Large}^{3}$ & $1367(93.3)$ & $413(92.0)$ & $954(93.9)$ & \\
\hline \multicolumn{5}{|l|}{ Education level } \\
\hline Low & $482(32.7)$ & $110(24.7)$ & $372(36.4)$ & $<0.001$ \\
\hline Medium & $555(37.7)$ & $164(37.0)$ & $391(38.1)$ & \\
\hline High & $142(9.7)$ & $54(12.0)$ & $88(8.5)$ & \\
\hline Very high & 292 (19.9) & 117 (26.3) & 175 (17.0) & \\
\hline Comorbidities $^{4}$ & 906 (57.4) & 341 (73.5) & $565(52.2)$ & $<0.001$ \\
\hline Type 2 diabetes & 459 (29.6) & $182(39.1)$ & $277(25.5)$ & $<0.001$ \\
\hline Hypertension & $532(34.4)$ & $208(44.8)$ & $326(30.1)$ & $<0.001$ \\
\hline Dyslipidemia & $388(25.1)$ & $163(35.1)$ & 225 (20.8) & $<0.001$ \\
\hline Arthritis & $101(6.5)$ & $24(5.2)$ & $77(7.2)$ & 0.15 \\
\hline Sleep apnea & $60(3.9)$ & $27(5.8)$ & $33(3.2)$ & 0.01 \\
\hline Other morbidities & $153(9.9)$ & $33(7.1)$ & $120(11.1)$ & 0.02 \\
\hline \multicolumn{5}{|l|}{ Ethnicity } \\
\hline Dutch & $1242(83.1)$ & 399 (88.5) & $843(80.9)$ & 0.03 \\
\hline Other & $251(16.8)$ & $52(11.5)$ & 199 (19.1) & \\
\hline
\end{tabular}

$\mathrm{N}=100 \%$; age SE mean: 0.37 . Missing: age $\mathrm{n}=0$; BMI $\mathrm{n}=7$; weight $\mathrm{n}=4$; waist $\mathrm{n}=115$; education level $\mathrm{n}=75$; ethnicity $\mathrm{n}=3$. ${ }^{1}$ small $<94 \mathrm{~cm}$ male; $<80 \mathrm{~cm}$ female; ${ }^{2}$ medium $94-102 \mathrm{~cm}$ male; $80-88 \mathrm{~cm}$ female; ${ }^{3}$ large $>102 \mathrm{~cm}$ male; $>88 \mathrm{~cm}$ female. ${ }^{4}$ comorbidities do not add up to $100 \%$ because patients have several comorbidities at the same time. 
Table 2 Measurements

\begin{tabular}{|c|c|}
\hline Phase & Measurement \\
\hline \multicolumn{2}{|l|}{ Baseline } \\
\hline Patient & $\begin{array}{l}\text { Date of birth; gender; stature; weight; waist circumference; ethnicity; educational level; diet history; } \\
\text { reasons for weight loss; referral; treatment expectations; self-reported morbidities including: type } 2 \text { diabetes } \\
\text { mellitus; hypertension; dyslipidaemia; osteoarthritis; sleep apnoea; stomach pains; chronically obstructive } \\
\text { pulmonary disease (COPD); hypothyroidism; epilepsy; mental retardation; depression, psychiatric illness } \\
\text { and cancer [12-14]; medication, smoking habits }\end{array}$ \\
\hline Dietitian & Years of experience, number of patients treated per year; skills and training. \\
\hline Management & $\begin{array}{l}\text { Several questions on food habits; type of treatment; exercise (frequency and duration); used folders and } \\
\text { other materials; stage of change; patients own estimation of motivation and success. }\end{array}$ \\
\hline \multicolumn{2}{|c|}{ Follow-up 6 months } \\
\hline Patient & $\begin{array}{l}\text { Weight; waist circumference. If working and social situation has changed; if comorbidities have changed; } \\
\text { referral to other health workers; smoking habits; what patients do to maintain their weight loss. }\end{array}$ \\
\hline Dietitian & $\begin{array}{l}\text { Counselling techniques used; judgement of dietitian if and how much the type of treatment, exercise, } \\
\text { personal effectiveness, social support, and mental condition have contributed to successful weight loss. }\end{array}$ \\
\hline Management & $\begin{array}{l}\text { Type of treatment; exercise in frequency and duration; number of consultations; duration of treatment. } \\
\text { Which parts of the treatment have been successful: changes in eating behaviour; more exercise; better } \\
\text { physical condition; coping with emotions or social environment; improvement of mental wellbeing } \\
\text { and/or personal effectiveness? Is treatment continued or has it ended; why treatment has ended; } \\
\text { if relapse has occurred. }\end{array}$ \\
\hline \multicolumn{2}{|c|}{ Follow-up 12 and 24 months } \\
\hline Patient & $\begin{array}{l}\text { Weight; waist circumference. If working and social situation has changed; if comorbidities have changed; } \\
\text { referral to other health workers; smoking habits; what patients do to maintain their weight loss. }\end{array}$ \\
\hline Dietitian & $\begin{array}{l}\text { Counselling techniques; judgement of dietitian if and how much the type of treatment, exercise, personal } \\
\text { effectiveness, social support, and mental condition have contributed to successful weight loss. If the } \\
\text { dietitian has taken up education to improve her skills in counselling }\end{array}$ \\
\hline Management & $\begin{array}{l}\text { Type of treatment; exercise in frequency and duration; number of consultations; duration of treatment. } \\
\text { Which parts of the treatment have been successful: changes in eating behaviour; more exercise; better } \\
\text { physical condition; coping with emotions or social environment; improvement of mental wellbeing and/or } \\
\text { personal effectiveness? Is treatment continued or has it ended; why treatment has ended; if relapse } \\
\text { has occurred }\end{array}$ \\
\hline
\end{tabular}

Table 3 Comparison of cohort with data of survey

\begin{tabular}{lll}
\hline & National survey $\mathbf{2 0 0 7}$ & Current study 2007 \\
\hline Number of patients recorded & 4634 & 1546 \\
Number of practices* & 22 & 26 \\
$\begin{array}{l}\text { Number of patients overweight } \\
\text { or obese }\end{array}$ & $1955(42.2 \%)$ & $619(40.0 \%)$ \\
Number of patients with overweight or obesity and comorbidities & $2237(48.2 \%)$ & $906(57.4)$ \\
Male & $33.2 \%$ & $30.1 \%$ \\
Female & $66.8 \%$ & $69.9 \%$ \\
Mean age (years) & 45.5 & 49.7 \\
Total number of patients treated for weight & $3503(75.5 \%)$ & $1525(97.4 \%)$ \\
Social economic status & & $32.7 \%$ \\
$\quad$ Low & $33.7 \%$ & $37.7 \%$ \\
$\quad$ Medium & $41.7 \%$ & $9.7 \%$
\end{tabular}

*Practices in national survey were all stand-alone practices. In our study practices were a mix of stand-alone and large practices of more than 5 dietitians. 
Table 4 Different characteristics * of adults that visit the dietitian for weight management

\begin{tabular}{|c|c|c|c|c|}
\hline & Total sample (\%) & Male (\%) & Female (\%) & Chi square test $P$ value \\
\hline \multicolumn{5}{|l|}{ Previous weight loss attempts } \\
\hline No attempt & $454(29.6)$ & $224(48.4)$ & $230(21.4)$ & $<0.001$ \\
\hline 1 time & $334(21.7)$ & $110(23.8)$ & $224(20.8)$ & \\
\hline 2 times & $156(10.1)$ & $48(10.4)$ & $108(10.0)$ & \\
\hline$\geq 3$ times $^{1}$ & $594(38.6)$ & $81(17.4)$ & $513(47.8)$ & \\
\hline \multicolumn{5}{|l|}{ Referral } \\
\hline General practitioner & $686(44.3)$ & $270(58.2)$ & $416(38.4)$ & $<0.001$ \\
\hline Patient asked for referral & $738(47.7)$ & $155(33.3)$ & $583(53.9)$ & $<0.001$ \\
\hline Medical Specialist & $110(7.1)$ & $34(7.4)$ & $76(7.0)$ & 0.66 \\
\hline Psychologist & $12(0.8)$ & $1(0.2)$ & $11(1.0)$ & 0.10 \\
\hline Occupational health physician & $5(0.3)$ & $4(0.9)$ & $1(0.9)$ & 0.01 \\
\hline \multicolumn{5}{|l|}{ Expectations $^{2}$} \\
\hline To lose weight & $1191(77.0)$ & $352(76.0)$ & $839(77.5)$ & 0.41 \\
\hline Firm guidance & $949(61.4)$ & $251(53.8)$ & $698(64.6)$ & $<0.001$ \\
\hline Nutritional advice & $620(40.2)$ & $219(47.4)$ & $401(37.5)$ & 0.001 \\
\hline A written diet & $249(16.2)$ & $60(12.9)$ & $189(17.9)$ & 0.02 \\
\hline To weigh every week & $34(2.3)$ & $7(1.7)$ & $29(2.5)$ & 0.22 \\
\hline Help overcome binge eating & $120(7.8)$ & $13(2.8)$ & $107(9.8)$ & $<0.001$ \\
\hline Help with relapse & $206(13.4)$ & $40(8.6)$ & $166(15.3)$ & $<0.001$ \\
\hline Recipes/menus & $110(7.1)$ & $26(5.6)$ & $84(7.8)$ & 0.13 \\
\hline \multicolumn{5}{|l|}{ Other treatment outcomes ${ }^{2}$} \\
\hline To look better & $552(35.7)$ & $109(23.5)$ & $443(40.9)$ & $<0.001$ \\
\hline Better health & $1269(82.1)$ & $409(88.3)$ & $860(79.4)$ & $<0.001$ \\
\hline Feel physically fit & $636(41.1)$ & $168(36.2)$ & $468(43.2)$ & 0.01 \\
\hline More self confidence & $269(17.4)$ & $31(6.7)$ & $238(22.1)$ & $<0.001$ \\
\hline
\end{tabular}

*Previous weight loss attempts, initiative for referral, patients' treatment expectations and other treatment outcomes. ${ }^{1} T h i s$ value includes using medication to lose weight $(n=25) .{ }^{2}$ Values do not add up to $100 \%$ because patients were allowed to give several answers. Missing: previous weight loss attempts 8 ; referral 0 ; expectations 11 ; other treatment outcomes 7.

recruitment period of three months and the suggestion to recruit consecutive patients. Each patient signed an informed consent form. The dietitians filled out a questionnaire for each included patient that visited their practice for weight loss treatment at the first consultation. The general practitioner of each patient was informed by a letter that was added to the report the dietitian sent to the general practitioner after the first consultation.

Inclusion criteria were: all patients aged older than eighteen years who visited the dietitian for treatment for overweight or obesity with or without morbidities. No maximum age was set and the only exclusion criterion was pregnancy at the start of the treatment. We asked each dietitian to include at least ten patients. Approval for the study was obtained from the Medical Ethical Committee of VU University Medical Centre, Amsterdam, the Netherlands.

\section{Study sample}

We distributed 3000 patient baseline questionnaires to 190 dietitians to be completed. Questionnaires were based on the outcomes of the expert meeting, and on a pilot study we carried out. We chose to start an observational study because it was unclear which patients were seen by the dietitian for weight management. To our knowledge no validated questionnaires on referral, treatment expectations, previous weight loss attempts and other treatment outcomes are available. Therefore we developed questionnaires ourselves. We obtained completed questionnaires from baseline data of 154 dietitians (81\%). Dietitians completed all forms themselves. We asked them to do so because we wanted as high a response rate as possible with comparable outcomes, e.g. standardised weighing and measuring. We received data on 1546 adults, 464 men (30\%) and 1082 women (Table 1). 
Table 5 Personal characteristics, expectations and treatment goals related to weight related health risk in men

\begin{tabular}{llllll}
\hline $\mathbf{N}=\mathbf{4 6 4}$ & No/Light risk (\%) & High risk (\%) & Very high risk (\%) & Extremely high risk (\%) & Chi-square test $\mathbf{P}$ value \\
\hline Total & $23(5.0)$ & $137(29.7)$ & $188(40.8)$ & $113(24.5)$ & 0.01 \\
Age & & & & & \\
$\quad$ Young & $9(11.0)$ & $28(34.1)$ & $32(39.0)$ & $13(15.0)$ & $<0.001$ \\
$\quad$ Middle aged & $9(3.9)$ & $63(26.8)$ & $92(39.1)$ & $70(30.2)$ & \\
$\quad$ Old & $2(1.4)$ & $48(32.4)$ & $67(45.3)$ & $31(20.9)$ &
\end{tabular}

Education level

$\begin{array}{lllll}\text { Low } & 2(1.8) & 27(24.5) & 47(42.7) & 34(30.9) \\ \text { Medium } & 2(1.2) & 51(31.3) & 76(46.6) & 34(20.9) \\ \text { High } & 5(9.3) & 11(20.4) & 22(40.7) & 16(29.6) \\ \text { Very high } & 14(20.2) & 40(34.8) & 38(33.0) & 23(20.0)\end{array}$

\section{Ethnicity}

$\begin{array}{ll}\text { Dutch } & 15(3.8) \\ \text { Other ethnicities } & 7(13.4) \\ \text { morbidities }^{2} & \\ \text { Type 2 diabetes } & 1(0.6) \\ \text { Hypertension } & 3(1.5) \\ \text { Dyslipedemia } & 3(1.9) \\ \text { Arthritis } & 0(0) \\ \text { Sleep apnoea } & 0(0) \\ \text { Other morbidities } & 4(12.2)\end{array}$

$\begin{array}{lll}119(30.1) & 163(41.2) & 99(25.0) \\ 14(26.9) & 21(40.4) & 10(19.3)\end{array}$

\section{Previous weight loss attempts}

$\begin{array}{ll}\text { Never diet } & 17(7.7) \\ 1 \text { time } & 1(0.9) \\ 2 \text { times } & 1(2.1) \\ \geq 3 \text { times } & 4(5.0)\end{array}$

Referral

$\begin{array}{ll}\text { General Practioner } & 6(2.5) \\ \text { Patient asked } & 17(10.6) \\ \text { Medical Specialist } & 0 \\ \text { Psychologist } & 0 \\ \text { Occupational health physician } & 1(0.25)\end{array}$

\section{Treatment goal ${ }^{3}$}

$\begin{array}{ll}\text { To lose weight } & 17(4.9) \\ \text { Firm guidance } & 10(4.0) \\ \text { Nutritional advice } & 10(4.7) \\ \text { A written diet } & 4(6.6) \\ \text { To weigh every week } & 0 \\ \text { Overcome binge eating } & 2(15.4) \\ \text { Help with relapse } & 3(7.5) \\ \text { Recepies/menus } & 2(8.0)\end{array}$

$\begin{array}{ll}40(22.1) & 86(47.5) \\ 40(19.5) & 89(34.4) \\ 40(24.8) & 74(46.0) \\ 2(8.3) & 13(54.2) \\ 2(7.4) & 11(40.7) \\ 14(42.4) & 12(36.4)\end{array}$

$54(29.8)$

0.01

73 (35.6) $\quad<0.001$

$44(27.3) \quad 0.047$

9 (37.5)

0.091

$14(51.9) \quad 0.005$

$3(9.1)$

0.019

$74(33.5) \quad 101(45.7)$

$29(13.1)$

$<0.001$

$34(30.9)$

$43(39.1)$

$32(29.1)$

$12(25.0)$

20 (41.7)

15 (31.3)

$17(21.0)$

$24(29.6)$

$36(44.4)$

$\begin{array}{llll}65(26.6) & 108(44.3) & 65(26.6) & 0.74 \\ 58(36.0) & 48(29.8) & 38(23.6) & 0.67 \\ 10(29.4) & 16(47.1) & 8(43.5) & 0.58 \\ 0 & 1(100.0) & 0 & - \\ 0 & 1(0.25) & 2(0.50) & -\end{array}$

$\begin{array}{ll}106(30.4) & 136(39.0) \\ 67(26.90) & 102(41.0) \\ 72(33.3) & 87(40.3) \\ 15(25.0) & 25(41.7) \\ 1(14.3) & 2(28.6) \\ 1(7.7) & 4(30.8) \\ 6(15.0) & 12(30.0) \\ 7(28.0) & 7(28.0)\end{array}$

$90(25.8)$

0.42

$70(28.1)$

0.23

$47(21.8) \quad 0.43$

$16(26.7) \quad 0.86$

$4(57.1) \quad 0.37$

$6(46.2) \quad 0.05$

$19(47.5) \quad 0.004$

$9(36.0) \quad 0.44$ 
Table 5 Personal characteristics, expectations and treatment goals related to weight related health risk in men (Continued)

\begin{tabular}{|c|c|c|c|c|}
\hline \\
\hline \multicolumn{5}{|c|}{$\begin{array}{l}\text { Other treatment outcomes } \\
\text { To look better }\end{array}$} \\
\hline Better health & $17(4.2)$ & 116 (28.6) & $169(41.7)$ & $103(25.4)$ \\
\hline Feel fit & $8(4.8)$ & $42(25.1)$ & 64 (38.3) & $53(31.7)$ \\
\hline Self confidence & $3(9.7)$ & $10(32.3)$ & $5(16.1)$ & $13(41.9)$ \\
\hline
\end{tabular}

\section{Measurements}

Measurements are shown in Table 2. The questions and response categories at baseline were based on data from an expert meeting, data from a pilot study [12] and on experiences of the dietitians who have treated patients for overweight and obesity. Patients were classified in 5 BMI categories (BMI <25, 25-29.9; 30-34.5; 35-39.9 and $\geq 40 \mathrm{~kg} / \mathrm{m}^{2}$ and three categories of waist circumference ( $<94$ or $80 \mathrm{~cm}$; $94-102$ or $80-88 \mathrm{~cm}$, and $>102$ or $>88 \mathrm{~cm}$ ) [13], and in weight related health risk (WRHR): no WRHR (BMI 20-25 kg/m²); light WRHR (BMI 25-30 kg/m with waist $<102 \mathrm{~cm}($ male) $/<88 \mathrm{~cm}$ (female), without comorbidities); high WRHR (BMI 25-30 kg/m ${ }^{2}$ with waist $\geq 102 / 88 \mathrm{~cm}$ with comorbidities, or BMI $30-35 \mathrm{~kg} / \mathrm{m}^{2}$ without comorbidities); very high WRHR (BMI 30-35 kg/m² with comorbidities, or BMI $35-40 \mathrm{~kg} / \mathrm{m}^{2}$ without comorbidities), and extremely high WRHR (BMI 35-40 kg/m² with comorbidities or BMI $>40 \mathrm{~kg} / \mathrm{m}^{2}$, regardless of comorbidities) $[14,15]$. The categories no and light WRHR were combined because of small numbers.

We instructed the dietitians to measure waist circumference with the patient standing up after a normal expiration. The waist was measured mid-way between the top of the hip bone and the lowest rib. The patients were weighed and height was measured by the dietitians in the practice.

We classified type 2 diabetes mellitus, hypertension, dyslipidaemia, sleep apnoea and arthritis as comorbidities $[13,15]$.

We distinguished two ethnic groups: Dutch and other ethnicities (Moroccan, Turkish, and Surinamese/ Antillean and other countries). Education level was split into four levels: low (primary and secondary school), medium (professional training at secondary level), high (high school), very high (higher professional education or university) [16]. The history of previous weight loss attempts was categorized into four levels: no previous weight loss attempts, one, two, and three or more previous attempts. Within the last category was also included the use of medication to achieve weight loss $(n=25)$. Referral was categorized into five categories: general practitioner, medical specialist, and psychologist, youth care physician and occupational health physician.

\section{Analysis}

We analysed the data stratified by gender using SPSS 19.0 (IBM SPSS, 2012). For Tables 2, 3, 4 and 5 we performed crosstabs with Chi-squared tests. To adjust for multiple testing we considered a more strict P-value $(<0.005)$ as statistically significant. For Tables 6 and 7 we conducted multivariate, multinomial logistic regression analyses to determine whether age, education level, ethnicity, other morbidities (those not included in the assessment of weight related health risk), previous weight loss attempts and referral were associated with weight related health risk as dependent variable. Potential clustering was not adjusted for in the analyses.

\section{Results}

In total 154 dietitians, which meant $24 \%$ of all dietitians in the Netherlands working in primary care at the time of our study, working in 26 practices returned 1549 questionnaires, of which 1546 could be used for analysis (Figure 1). Three questionnaires were excluded because birthdates were missing. The practices were distributed evenly across the country. From all 12 provinces in the Netherlands two or three practices participated. The mean number of patients included in the study was 60 per practice $(S D \pm 10.4)$. Per dietitian the mean number of recruited patients was $10(\mathrm{SD} \pm 7.2)$. To examine the representativeness of our sample we compared these data to a national survey (Table 3 ).

We divided the study population into three age groups (19-44; 45-64; and 65 years and older). The numbers in these age groups were 402; 749 and 395 patients respectively. Differences between men and women in level of obesity, age group, waist circumference, education level, co morbidities, and ethnicity were tested using a Chisquare test (Table 1). The sex differences in history of 
Table 6 Personal characteristics, expectations and treatment goals related to weight related health risk in women

$\mathrm{N}=1082$

Age

\section{Young}

Middle aged

Old

Education level

$\begin{array}{ll}\text { Low } & 7(1.9) \\ \text { Medium } & 30(7.7) \\ \text { High } & 7(7.9) \\ \text { Very high } & 18(10.3)\end{array}$

\section{Ethnicity}

Dutch
Other ethnicities

\section{Comorbidities $^{2}$}

$\begin{array}{ll}\text { Type } 2 \text { diabetes } & 0 \\ \text { Hypertension } & 0 \\ \text { Dyslipedemia } & 0 \\ \text { Arthritis } & 0(0) \\ \text { Sleep apnea } & 1(2.9) \\ \text { Other morbidities } & 11(9.1)\end{array}$

Previous weight loss attempts

$\begin{array}{ll}\text { Never diet } & 16(7.0) \\ 1 \text { time } & 12(5.4) \\ 2 \text { times } & 10(9.3) \\ \geq 3 \text { times } & 25(4.9)\end{array}$

Referral

$\begin{array}{ll}\text { General practioner } & 5(1.3) \\ \text { Patient asked } & 54(8.9) \\ \text { Medical specialist } & 3(4.6) \\ \text { Psychologist } & 1(12.5) \\ \text { Occupational health physician } & 0\end{array}$

Treatment goal ${ }^{3}$

$\begin{array}{ll}\text { To lose weight } & 51(6.1) \\ \text { Firm guidance } & 41(5.9) \\ \text { Nutritional advice } & 28(7.0) \\ \text { A written diet } & 7(3.7) \\ \text { To weigh every week } & 0 \\ \text { Overcome binge eating } & 12(11.2) \\ \text { Help with relapse } & 10(6.0) \\ \text { Recepies/menus } & 9(10.8)\end{array}$

$21(4.3)$

\begin{tabular}{lllll} 
No/Light risk (\%) & High risk (\%) & Very high risk (\%) & Extremely high risk (\%) & Chi-square test $\mathbf{P}$ value \\
\hline $64(5.9)$ & $404(37.5)$ & $348(32.3)$ & $261(24.2)$ & 0.01
\end{tabular}

$38(12.1)$

$153(47.8) \quad 71(21.7)$

$59(18.4)$

$<0.001$

$188(36.6)$

$172(33.3)$

$133(25.8)$

$65(26.9)$

$110(44.2)$

$70(28.1)$

$\begin{array}{lll}109(29.6) & 145(39.4) & 107(29.1) \\ 158(40.5) & 110(28.2) & 92(23.6) \\ 34(38.6) & 32(36.4) & 15(17.0) \\ 87(49.7) & 40(22.9) & 30(17.1)\end{array}$

$310(37.0)$

276 (32.9)

196 (23.4)

0.35

78 (39.2)

$63(31.6)$

$52(26.2)$

$\begin{array}{ll}51(18.58) & 116(42.5) \\ 61(18.85) & 135(41.7) \\ 70(31.1) & 96(42.7) \\ 11(14.5) & 35(46.1) \\ 4(11.8) & 13(38.2) \\ 60(49.6) & 26(21.5)\end{array}$

109 (39.5)

$<0.001$

128 (39.5)

$<0.001$

$59(26.2)$

$<0.001$

$30(39.5)$

$<0.001$

$16(47.1)$

0.002

24 (19.8)

0.001

106 (46.3) $71(31.0)$

36 (15.73)

0.002

87 (39.0)

75 (33.6)

$49(22.0)$

$41(40.2)$

31 (29.06)

23 (21.5)

165 (32.3)

168 (32.9)

$153(29.9)$

$\begin{array}{ll}118(31.8) & 133(35.3) \\ 261(42.9) & 181(29.7) \\ 20(27.4) & 24(32.9) \\ 3(37.5) & 1(12.5) \\ 0 & 0\end{array}$

121 (32.1)

$<0.001$

113 (18.6)

$<0.001$

26 (35.6)

0.37

3 (37.5)

0.12

0

$\begin{array}{llll}320(38.2) & 270(32.3) & 196(23.4) & 0.24 \\ 254(36.6) & 224(32.2) & 177(25.43) & 0.23 \\ 170(52.9) & 121(30.5) & 78(19.6) & 0.05 \\ 69(36.9) & 68(33.7) & 43(25.7) & 0.45 \\ 15(51.9) & 9(33 .) & 4(14.8) & 0.38 \\ 34(31.8) & 34(31.8) & 27(25.2) & 0.13 \\ 57(34.5) & 50(30.3) & 48(29.1) & 0.55 \\ 29(34.9) & 28(33.7) & 17(20.5) & 0.21\end{array}$


Table 6 Personal characteristics, expectations and treatment goals related to weight related health risk in women (Continued)

\begin{tabular}{|c|c|c|c|c|c|}
\hline \multicolumn{6}{|c|}{ Other treatment outcomes ${ }^{3}$} \\
\hline To look better & $41(9.3)$ & $192(43.3)$ & $134(30.2)$ & $76(17.2)$ & $<0.001$ \\
\hline Better health & $27(3.2)$ & $308(35.9)$ & $295(34.4)$ & $227(26.5)$ & $<0.001$ \\
\hline Feel fit & $219(4.6)$ & $175(37.8)$ & $159(34.3)$ & $108(23.3)$ & 0.42 \\
\hline Self confidence & $28(11.7)$ & $106(44.2)$ & $61(25.4)$ & 45 (18.8) & $<0.001$ \\
\hline
\end{tabular}

No health risk: BMI $20-25 \mathrm{~kg} / \mathrm{m}^{2}$. Light risk: BMI $25-30 \mathrm{~kg} / \mathrm{m}^{2}$ with waist $<88 \mathrm{~cm}$, without comorbidities ${ }^{*}$. High risk: $\mathrm{BMl} 25-30 \mathrm{~kg} / \mathrm{m}^{2}$ with waist $\geq 88 \mathrm{~cm}$, with comorbidities, and BMI $30-35 \mathrm{~kg} / \mathrm{m}^{2}$ without comorbidities. Very high risk: BMI $30-35 \mathrm{~kg} / \mathrm{m}^{2}$ with comorbidities, BMI $35-40 \mathrm{~kg} / \mathrm{m}^{2}$ without comorbidities. Extremely high risk: BMI $35-40 \mathrm{~kg} / \mathrm{m}^{2}$ with comorbidities and BMI $>40 \mathrm{~kg} / \mathrm{m}^{2}$, regardless of co morbidities.

${ }^{1}$ patients with $\mathrm{BMl}<25 \mathrm{~kg} / \mathrm{m}^{2}$ were included in light risk: $\mathrm{n}=14$. ${ }^{2}$ Comorbidities are: type 2 diabetes mellitus, hypertension, dyslipedemia, and arthritis and sleep apnoea. ${ }^{3}$ Values do not add up to 1082 because patients were allowed to give more than one answer; percentages add up within their category. Missing: gender 5; age 5; education level 61; ethnicity 45; previous weight loss attempts 12; referral 15.

previous weight loss attempts, referral and treatment expectations were also tested with a Chi-square test (Table 4). The associations between weight related health risk levels and categorical variables including age group, education level, ethnicity, number of comorbidities, frequency of previous diet attempts, referral, treatment goals and treatment outcomes other than weight loss, were analysed with a Chi-square test as well (Tables 5 and 6).

Of the sample $25 \%$ was overweight; the majority (73\%) was obese $\left(B M I \geq 30 \mathrm{~kg} / \mathrm{m}^{2}\right)$; and $10 \%$ had a BMI of $40 \mathrm{~kg} / \mathrm{m}^{2}$ or more. Ninety per cent had a large waist circumference ( $\geq 88 \mathrm{~cm}$ in women; $\geq 102 \mathrm{~cm}$ in men). More than half of the sample had morbidities. Men had significantly more often type 2 diabetes mellitus $(\mathrm{P}<0.001)$, hypertension $(\mathrm{P}<0.001)$, and dyslipidaemia $(\mathrm{P}<0.001)$ than women.

Women reported more often a history of weight loss attempts, asked for referral more often themselves, and also showed a higher prevalence in their treatment expectation to gain more self-confidence $(\mathrm{P}<0.001)$ (Table 4).

The weight related health risk (WRHR) in relation to sex, age, diet history, and referral and patient treatment goals is presented in Tables 5 and 6. The majority of included patients had a high or very high WRHR. An extremely high WRHR was seen in $24.5 \%$ of the sample; $5.6 \%$ of the population did not have an increased WRHR. A higher WRHR was related to older age; a lower education level; more previous weight loss attempts; hypertension and the treatment expectation to improve one's health in men. In women a higher WRHR was related to older age; lower education level; all comorbidities; more previous weight loss attempts; referral, and to treatment expectations like losing weight for a better appearance and better health. A low socioeconomic status was seen in $32.7 \%$ of patients and a medium status in $37.7 \%$. A high to very high status was seen in $9 \%$ and $19.9 \%$ respectively.
Multivariate, multinomial logistic regression analyses (Tables 7 and 8) showed whether these associations were still present after adjustment for other variables. Middle age was consistently associated with a higher risk of very high and extremely high WRHR in men and women. In women, old age was also associated with a higher risk of very high and extremely high WRHR. Having other morbidities was associated with a lower risk of extremely high WRHR in men and women, and a lower risk of very high WRHR in women. Patients who asked for referral themselves had a lower risk of very high WRHR in men (odds ratio (OR) 0.60) and both very high and extremely high WRHR in women (OR 0.64 and OR 0.40).

\section{Discussion}

The study was effective in recruiting dietitians to participate. The sample is representative for dietitians working in primary care, as well as for patients visiting the dietitian in primary care, compared to a national survey (Table 3). The majority of patients were female, which is in line with the national survey and other patient populations [6,7], but higher than the samples of several other studies $[17,18]$. The men in our study had more comorbidities (73.5\%) compared to women (52.2\%), but in women weight related health risk was stronger related to comorbidities. This is not consistent with for example the large cohort of Booth et al., who found that comorbidities in men and women were quite similar [19].

In both men and women a high to very high education level was weakly related to a lower WRHR. The high number of patients with a high to very high education level in our cohort is in line with the recent development that obesity is now spread across all SES levels [20]. Our results corroborate that obese patients have a complex profile. In these patients weight management includes dietary treatment of the comorbidities at the same time, thus complicating the treatment. Because of these complexities, weight management should be adjusted to the individual and carried out by dietitians, 
Table 7 Results from multivariate multinomial regression analysis with weight related health risk as dependent variable; with no to high weight related health risk as reference in men

\begin{tabular}{lll}
\hline Very high weight related health risk & Odds ratio & $\mathbf{9 5 \%} \mathbf{C l}$ \\
\hline Age & & \\
Young (reference) & 1.0 & \\
$\quad$ Middle age & 1.73 & $(0.92-3.25)$ \\
Old & 1.28 & $(0.92-1.80)$
\end{tabular}

Education level

High/very high (reference)

Medium

1.0

Low

Ethnicity

Dutch (reference)

Other

Other morbidities

No comorbidities (reference)

Other morbidities

$(0.23-1.19)$

Previous weight loss attempts

$\begin{array}{lll}\text { None (reference) } & 1.0 & \\ 1 \text { or } 2 \text { attempts } & 1.25 & (0.73-2.13) \\ 3 \text { or more attempts } & 1.37 & (0.85-2.21)\end{array}$

Referral

General practitioner (reference) $\quad 1.0$

Self-referred

0.60

(0.34-1.08)

Other health professionals

1.04

(0.45-2.39)

\begin{tabular}{lll}
\hline Extremely high weight related health risk & Odds ratio & $\mathbf{9 5 \%} \mathrm{Cl}$ \\
\hline Age & & \\
Young (reference) & 1.0 & \\
$\quad$ Middle age & 3.72 & $(1.64-8.48)$ \\
Old & 1.42 & $(0.91-2.23)$
\end{tabular}

Education level

High/very high (reference)

1.0

Medium

Low

Ethnicity

Dutch (reference)

Other

Other morbidities

No comorbidities (reference)

Other morbidities

Previous weight loss attempts

None (reference)
1 or 2 attempts
3 or more attempts

Table 7 Results from multivariate multinomial regression analysis with weight related health risk as dependent variable; with no to high weight related health risk as reference in men (Continued)

\begin{tabular}{lll}
\hline Referral & & \\
General practitioner (reference) & 1.0 & \\
Self-referred & 0.87 & $(0.45-1.70)$ \\
Other health professionals & 0.70 & $(0.24 / 2.02)$
\end{tabular}

*includes stomach pains; chronically obstructive pulmonary disease (COPD); hypothyroidism; epilepsy; mental retardation; depression, psychiatric illness and cancer.

who have a thorough training in nutrition, dietetics and behaviour, and who can adjust the treatment to the needs, possibilities and expectations of the individual patient to promote lasting weight loss [5]. RD-led dietary instruction in the areas of energy restriction, dietary change, exercise, and behaviour modification was proven more beneficial than frequent weigh-in visits without the RD present in promoting weight loss [9]. A good patient-provider relationship has increasingly been recognized as a critical factor in patient's treatment adherence [21]. This is in line with the fact that dietitians view themselves as potential leaders in the field of weight management, and see this area as an important part of their role. Registered dietitians have extensive training and hold views that are current, and regularly employ many of the elements of known best practice in management [22]. The management of severely obese patients in primary care may also lead to successful weight loss in patients with morbid obesity [23]. The Dutch criteria for bariatric surgery are similar to the US guidelines: these patients are treated conservatively with diet and lifestyle for one year and are undergo surgery if conservative treatment does not lead to success [24]. Time trends show that the number of patients with a high to extremely high weight related health risk will increase in the near future $[25,26]$ and dietitians need to be prepared to meet this challenge.

\section{Main strengths and weaknesses}

Our sample consists of a representative sample of $24 \%$ of all dietitians working in primary care at the time of inclusion who have voluntarily enrolled in our study. The strengths of this study are the national scale on which it is carried out and the large number of dietitians included, as well as the amount of information about the patients that was collected. These detailed data add to the knowledge of this area of health care.

When we look at geographical dispersal and the balance between larger practices with many dietitians and small private practices the representativeness of our population is sufficient. 
Table 8 Results from multivariate multinomial regression analysis with weight related health risk as dependent variable; with no to high weight related health risk as reference in women

\begin{tabular}{lll}
\hline Very high weight related health risk & Odds ratio & $\mathbf{9 5 \%} \mathbf{C l}$ \\
\hline Age & & \\
$\quad$ Young (reference) & 1.0 & \\
$\quad$ Middle age & 2.25 & $(1.54-3.26)$ \\
$\quad$ Old & 1.97 & $(1.58-2.47)$ \\
Education level & & \\
$\quad$ High/very high (reference) & 1.0 & \\
$\quad$ Medium & 1.01 & $(0.70-1.48)$ \\
$\quad$ Low & 0.96 & $(0.79-1.16)$
\end{tabular}

Ethnicity

Dutch (reference) $\quad 1.0$

Other 0.89

$(0.60-1.33)$

Other morbidities

No comorbidities (reference) $\quad 1.0$

Other morbidities

$(0.28-0.78)$

Previous weight loss attempts

$\begin{array}{lll}\text { None (reference) } & 1.0 & \\ 1 \text { or } 2 \text { attempts } & 0.98 & (0.70-1.36) \\ 3 \text { or more attempts } & 1.15 & (0.84-1.57)\end{array}$

Referral

General practitioner (reference) $\quad 1.0$

Self-referred $\quad 0.65$

$(0.47-0.90)$

Other health professionals

1.17

$(0.65-2.11)$

\begin{tabular}{lll}
\hline Extremely high weight related health risk & Odds ratio & $\mathbf{9 5 \%} \mathbf{C l}$ \\
\hline Age & & \\
Young (reference) & 1.0 & \\
$\quad$ Middle age & 1.79 & $(1.20-2.67)$ \\
Old & 1.55 & $(1.22-1.98)$
\end{tabular}

Education level

High/very high (reference)

1.0

Medium

Low

1.08

Ethnicity

Dutch (reference)

Other

Other morbidities

No comorbidities (reference)

Other morbidities

$(0.39-0.90)$

Previous weight loss attempts

None (reference)

1 or 2 attempts

0.85

1.03

$(0.77-1.77)$

$(0.87-1.33)$
Table 8 Results from multivariate multinomial regression analysis with weight related health risk as dependent variable; with no to high weight related health risk as reference in women (Continued)

\begin{tabular}{lll}
\hline Referral & & \\
General practitioner (reference) & 1.0 & \\
Self-referred & 0.40 & $(0.48-0.56)$ \\
Other health professionals & 1.36 & $(0.75-2.47)$ \\
\hline
\end{tabular}

*includes stomach pains; chronically obstructive pulmonary disease (COPD); hypothyroidism; epilepsy; mental retardation; depression, psychiatric illness and cancer.

A limitation of this study is that we left it up to the dietitians how many patients to include. We have no information of patients that were not included, and who may have been more difficult to treat. A second reason causing selection bias was that some dietitians, who have affinity with treating obesity, have included more patients. Another limitation is that the dietitians and not the patients completed the questionnaires. We chose this method because we wanted to obtain standardised data on medical conditions and anthropometric measurements. On more subjective questions, for example on treatment expectations, our approach may have led to some misinterpretation.

\section{Conclusion}

The study was effective in recruiting dietitians to participate. The sample is representative for dietitians working in primary care. The majority of patients are female despite our efforts to include more men. The majority of patients (94\%) have a high to extremely high weight related health risk (WRHR).

Abbreviations

BMI: Body mass index; WRHR: Weight related health risk; RD: rRegistered dietitian.

Competing interests

The authors declare that they have no competing interests. The study is conducted by the department of Health Science of VU University, Amsterdam, the Netherlands. Funding was obtained from the department of Health Science of VU University to visit practices; as well as for printing, distributing and collecting questionnaires. All data are stored confidentially and anonymously. Data are handled according the Dutch Personal Data Protection Act. Data are not freely available in the public domain.

Authors' contributions

EG designed the study, and the questionnaires; she recruited dietitians and collected the data. She carried out the data analyses and drafted the article. JCs supervised the study and contributed to study design, the following (0.59-1.22) actions, the data analyses and composition of the article. MV supervised and contributed to study design, the following actions, the data analyses and composition of the article. IAB contributed to the study design, collection of data, the data analyses and composition of the article. All authors read and approved the final manuscript. 


\section{Acknowledgements}

The authors wish to thank the participating dietitians for their contribution in recruiting patients and completing questionnaires.

\section{Author details}

${ }^{1}$ Department of Health Sciences and the EMGO Institute for Health and Care Research, Faculty of Earth and Life Sciences, VU University Amsterdam, De Boelelaan 1085, 1081 HV Amsterdam, The Netherlands. ${ }^{2}$ Department of Epidemiology and Biostatistics, EMGO Institute for Health and Care Research, VU University Medical Center, Amsterdam, The Netherlands. ${ }^{3}$ Amstelring Foundation for Primary Care, Amstelveen, The Netherlands.

Received: 19 August 2013 Accepted: 14 August 2014 Published: 25 September 2014

\section{References}

1. Anonymous: Self-reported data on weight, smoking and lifestyle. In StatlineCBS.nl. 2012.

2. Visscher TLS, Viet AL, Kroesbergen HT, Seidell JC: Underreporting of body mass index in adults and its effect on obesity prevalence estimations in the period 1998-2001. Obesity 2006, 14:2054-2063.

3. Anonymous: Report of the expert meeting for dietitians treating weight loss in primary care. In Amsterdam, the Netherlands: Dutch Knowledge Centre for Obesity; 2005.

4. $\quad$ NIVEL (Dutch Institute for Primary Care Research): Yearbook LIPZ 2006-2007. In; 2008:38-45. ISBN978-90-6905-935-8.

5. Lammers M, Kok L: Cost - benefit Analysis of Dietary Treatment. Amsterdam: SEO Economic Research; 2012.

6. The Look AHEAD Group, Wing RR: Long-term effects of a lifestyle intervention on weight and cardiovascular risk factors in individuals with type 2 diabetes mellitus: four-year results of the look AHEAD trial. Arch Intern Med 2010, 170:1566-1575.

7. Weinstock RS, Trief PM, Cibula D, Morin PC, Delahanty LM: Weight loss success in metabolic syndrome by telephone interventions: results from the SHINE study. J Gen Intern Med 2013, 28:1620-1628.

8. Ashley JM, St Jeor ST, Schrage JP, Perumean-Chaney SE, Gilbertson MC, McCall NL, Bovee V: Weight control in the physician's office. Arch Intern Med 2001, 161:1599-1604.

9. Raatz SK, Wimmer JK, Kwong CA, Sibley SD: Intensive diet instruction by registered dietitians improves weight-loss success. J Am Diet Assoc 2008 , 108:110-113.

10. Grace C: A review of one-to-one dietetic obesity management in adults. J Hum Nutr Diet 2011, 24:13-22.

11. Keppie B, Lyon A: Evaluation of weight management services provided by dietitians within a community trust. J Hum Nutr Diet 1999, 12(Suppl s1):53-60.

12. Govers E, Brouwer IA, Kuijper LA, Visscher TLS, Seidell JC: Weight loss after one year and weight maintenance after four years after treatment by dieticians. Dutch J NutrDiet 2009, 64:51-56.

13. Anonymous: Obesity: preventing and managing the global epidemic In Report of a WHO consultation. Geneva: WHO Tech. Rep.Ser 894; 2000.

14. Seidell JC, de Beer JJ, Kuipers T: Guideline 'Diagnosis and treatment of obesity in adults and children'. Neth J Med 2008, 152:2071-2076.

15. Centre for Public Health Excellence at NICE (UK);National Collaborating Centre for Primary Care (UK): Obesity: the prevention, identification, assessment and management of overweight and obesity in adults and children. In NICE Clinical Guidelines No 43. London; 2006.

16. Anonymous: Socio-economic status in the Netherlands. In StatlineCBS. nl. 2012.

17. Norris SL, Zhang X, Avenell A, Gregg E, Brown TJ, Schmidt CH, Lau J: Long-term non-pharmacological weight loss interventions for adults with type 2 diabetes mellitus. London: The Cochrane Collaboration; 2006.

18. Wadden TA, Neiberg RH, Wing RR, Clark JM, Delahanty LM, Hill JO, Krakoff J, Otto A, Ryan DH, Vitolins MZ, Look AHEAD Research Group: Four-year weight losses in the look AHEAD study: factors associated with long-term success. Obesity 2011, 19:1987-1998.
19. Booth HP, Prevost AT, Gulliford MC: Impact of body mass index on prevalence of multimorbidity in primary care: cohort study. Fam Pract 2014, 31(1):38-43.

20. Bunkert NT, Rásky E, Großschädl F, Muckenhuber J, Freidl W: The influence of socioeconomic factors on health parameters in overweight and obese adults. PLoS One 2013, 8:e65407.

21. Von Korff M, Gruman J, Schaefer J, Curry SJ, Wagner EH: Collaborative management of chronic illness. Ann Intern Med 1997, 127:1097-1102

22. Campbell K, Crawford D: Management of obesity: attitudes and practices of Australian dietitians. Int J Obes Relat Metab Disord 2000, 24(6):701-10.

23. Buchwald H, Avidor $Y$, Braunwald E, Jensen MD, Pories W, Fahrbach K, Schoelles K: Bariatric surgery. A systematic review and meta- analysis. JAMA 2004, 292:1724-1737.

24. Ryan DH, Johnson WD, Myers VH, Prather TL, McGlone MM, Rood J, Brantley PJ, Bray GA, Gupta AK, Broussard AP, Barootes BG, Elkins BL, Gaudin DE, Savory RL, Brock RD, Datz G, Pothakamuri SR, McKnight GT, Stenlof K, Sjöström LV: Nonsurgical weight loss for extreme obesity in primary care settings: results of the Louisiana obese subjects study. Arch Intern Med 2010, 170:146-154

25. Catenacci VA, Hill JO, Wyatt HR: The obesity epidemic. Clin Chest Med 2009, 30:415-444.

26. Berghöfer A, Pischon T, Reinhold T, Apovian CM, Sharma AM, Willich SN: Obesity prevalence from a European perspective, a systematic review. BMC Public Health 2008, 8:200.

doi:10.1186/1471-2296-15-161

Cite this article as: Govers et al:: Weight related health status of patients treated by dietitians in primary care practice: first results of a cohort study. BMC Family Practice 2014 15:161.

\section{Submit your next manuscript to BioMed Central and take full advantage of:}

- Convenient online submission

- Thorough peer review

- No space constraints or color figure charges

- Immediate publication on acceptance

- Inclusion in PubMed, CAS, Scopus and Google Scholar

- Research which is freely available for redistribution

Submit your manuscript at www.biomedcentral.com/submit
C Biomed Central 